\title{
Optimization and characterization of a new lipopeptide biosurfactant produced by marine Brevibacterium aureum MSA13 in solid state culture
}

\author{
G. Seghal Kiran ${ }^{\text {a }}$, T. Anto Thomas ${ }^{\text {a }}$, Joseph Selvin ${ }^{\mathrm{a}, *}$, B. Sabarathnam ${ }^{\text {a }}$, A.P. Lipton ${ }^{\mathrm{b}}$ \\ ${ }^{a}$ School of Life Sciences, Bharathidasan University, Tiruchirappalli 620024, India \\ ${ }^{\mathrm{b}}$ Central Marine Fisheries Research Institute, Vizhinjam 695521, India
}

\section{A R T I C L E I N F O}

\section{Article history:}

Received 19 August 2009

Received in revised form 3 November 2009

Accepted 4 November 2009

Available online 2 December 2009

\section{Keywords:}

Biosurfactant

Actinobacterium

Optimization

Lipopeptide biosurfactant

Antimicrobial-lipopeptide

\begin{abstract}
A B S T R A C T
The biosurfactant production of a marine actinobacterium Brevibacterium aureum MSA13 was optimized using industrial and agro-industrial solid waste residues as substrates in solid state culture (SSC). Based on the optimization experiments, the biosurfactant production by MSA13 was increased to threefold over the original isolate under SSC conditions with pre-treated molasses as substrate and olive oil, acrylamide, $\mathrm{FeCl}_{3}$ and inoculums size as critical control factors. The strain B. aureum MSA13 produced a new lipopeptide biosurfactant with a hydrophobic moiety of octadecanoic acid methyl ester and a peptide part predicted as a short sequence of four amino acids including pro-leu-gly-gly. The biosurfactant produced by the marine actinobacterium MSA13 can be used for the microbially enhanced oil recovery processes in the marine environments.
\end{abstract}

(C) 2009 Elsevier Ltd. All rights reserved.

\section{Introduction}

Production of biosurfactants has been increased in recent years because of their biodegradability and reduced toxicity compared to synthetic surfactants, enhanced application in bioremediation, food emulsification, and in cosmetics and stable activity at extremes of $\mathrm{pH}$, salinity and temperature. The availability of raw materials for scaled-up production processes and acceptable production economics has widened the scope of biosurfactants. Most of the biosurfactants are produced from agricultural residues and from the industrial waste products. The main problem related to use of alternative substrates as culture medium is to find a waste with the right balance of nutrients that permits cell growth and product accumulation (Makkar and Cameotra, 1999). They thus have additional advantages from the viewpoint of resource replacement and recycling. Synthetic surfactants are commonly produced using a variety of chemical synthesis strategies, depending on the types and structure of the molecule desired. Biosurfactants can be produced on renewable substrates and it has the potential to replace chemically synthesized surfactants. The industrial demand for surfactants has increased to about 300\% within the US chemical industry during the last decade.

Biosurfactants are amphipathic molecules with both hydrophilic and hydrophobic moieties that partition preferentially at

\footnotetext{
* Corresponding author. Address: Department of Microbiology, Bharathidasan University, Tiruchirappalli 620024, India. Tel.: +91 431 2407082; fax: +91 431 2407045.

E-mail addresses: selvinj@rediffmail.com, jselvin@bdu.ac.in (J. Selvin).
}

the interface between fluid phases that have different degrees of polarity and hydrogen bonding, such as oil and water or air and water interfaces. This property explains their broad use in environmental applications. Pollution of sea by crude oil, mostly caused by stranding of tankers is one of the urgent and serious environmental issues over the world (Olivera et al., 2003). Chemical surfactants are used over few decades for the degradation of these hydrocarbons due to its high toxicity, and low degradability. However, the production cost of synthetic surfactants is not affordable for their use in larger ecosystems. Literature evidenced that the marine microbes are scarcely explored for the production of biosurfactants. The sponge-associated marine bacteria are current focus of bioactive leads from the marine environment (Selvin et al., 2009). Considering the growing awareness on the climate change issues, the greener processes for the production of biosurfactants from industrial waste and bioremediation of petroleum hydrocarbons using biosurfactants will greatly reduce the uses of chemicals and xenobiotics in the environment. This study aims to develop processes for the enhanced production of biosurfactant from a marine actinobacterium using industrial and agro-industrial solid waste residues as substrates in solid state culture (SSC).

\section{Methods}

\subsection{Isolation of marine actinobacteria}

Marine sponge Dendrilla nigra was collected from the southwest coast of India by SCUBA diving at $10-15 \mathrm{~m}$ depth. To avoid cross 
contamination, only unbroken samples were used for microbiological analysis. The specimens were kept $2 \mathrm{~h}$ in sterilized aged seawater (SAS) to remove loosely associated microorganisms from inner and outer sponge surfaces. It has been hypothesized that this process may eliminate non-associated bacteria from the host sponge by digestion. The samples were kept in a sterile incubator oven for $1 \mathrm{~h}$ at $40^{\circ} \mathrm{C}$ to dry the surface, immediately frozen and packed in sterile sip-lap bags. The voucher specimens were stored at $-20^{\circ} \mathrm{C}$. For the isolation of sponge-associated actinobacteria, $1 \mathrm{~cm}^{3}$ of sponge tissue was excised from the internal mesohyl area using a pair of sterile scissors. The excised portion was thoroughly washed three times with sterile SAS to remove any bacteria within current canals and then the tissue was homogenized with phosphate buffered saline using a tissue homogenizer. The resultant homogenate was serially diluted with SAS and preincubated at $40^{\circ} \mathrm{C}$ for $1 \mathrm{~h}$ for the activation of dormant cells. The aliquot was placed on various isolation media including marine sponge agar and standard media (HiMedia). The inoculated plates were incubated at $27^{\circ} \mathrm{C}$ for 14 days in dark. The morphologically distinct colonies were reisolated and maintained on actinomycetes isolation agar (HiMedia) at $4{ }^{\circ} \mathrm{C}$.

\subsection{Screening for biosurfactant producers}

Biosurfactant production was examined with drop collapsing test (Youssef et al., 2004) and oil displacement test (Morikawa et al., 1993). Lipase activity was measured using the tributyrin agar plates (Kiran et al., 2009). Emulsification activity was performed according to Paraszkiewicz et al. (1992). All the assays were performed in triplicate with distilled water as the control. The actinomycetes isolation agar medium incubated without inoculums was included as negative control in the screening as to determine the effect of media on the emulsification index of the isolate.

\subsection{Identification of biosurfactant producer}

The strain MSA13 was identified morphologically and biochemically according to the method of Lechavalier (1970) and the genomic DNA was obtained by the method of Ferrara et al. (2006). For the $16 \mathrm{~S}$ rRNA sequencing the PCR analysis was performed as follows: universal 16S rRNA eubacterial primer (5'-GAGTTTGATCCTGGCT CAG-3'; 5'-AGAAAGGAGGTGATCCAGCC-3') was used for the amplification of $16 \mathrm{~S}$ rRNA. The $16 \mathrm{~S}$ rRNA gene sequence obtained from the isolate MSA13 was compared with other bacterial sequences by using NCBI megaBLAST (http://blast.ncbi.nlm.nih.gov/Blast.cgi) for their pair wise identities. Multiple alignments of these sequences were carried out by Clustal W 1.83 version of EBI (www.ebi.ac.uk/ cgi-bin/clustalw/) with 0.5 transition weight. Phylogenetic trees were constructed in MEGA 4.0 version (www.megasoftware.net) using neighbor joining (NJ), minimum evolution (ME) and unweighted pair group method with arithmetic mean (UPGMA) algorithms. Nucleotide composition of each aligned sequence was predicted by BioEdit software package and the 16S rRNA sequence of MSA13 was deposited in NCBI with an accession number GQ153943. The polyketide synthase type II gene was retrieved from the producer strain MSA13 according to Selvin (2009). The polyketide synthase gene sequence was analysed using bioinformatics tools such as EBI-TRANSEQ (www.ebi.ac.uk/emboss/transeq/, http://www.ebi.ac.uk/emboss/transeq/), SWISS-PROT (http://www. expasy.ch/sprot/) database using BLASTn, tBLASTx and PSI-BLAST (http://www.ebi.ac.uk/Tools/psiblast/), DomPred (http://bioinf.cs. ucl.ac.uk/dompred/) and MEGA 4.0.

\subsection{Optimization of biosurfactant production under SSC conditions}

For the development of SSC, the production substrate was developed using agro-industrial and industrial waste. To find suit- able substrate for the development of SSC, agro-industrial waste such as wheat bran, ground nut oil cake, rice bran, and oil seed cake and industrial waste such as furnished leather powder, diesel contaminated soil, petrol bunk soil, aavin (milk processing waste) pre-treated sludge, aavin (milk processing waste) treated waste, tannery pre-treated sludge, treated molasses (distillery waste), pre-treated molasses (distillery waste), and tannery treated sludge were used for the screening. Based on the screening results, six substrates including the industrial and agro-industrial wastes such as oil seed cake, wheat bran, tannery treated sludge, tannery pre-treated sludge, treated molasses and pre-treated molasses were used in the SSC development. The treated waste is collected after the effluent/waste treatment process and the pre-treated waste are prior to the treatment process. All the substrates were dried to ensure moisture free at $60{ }^{\circ} \mathrm{C}$ in an oven (Technico). Considering the significance of moisture content on the development of SSC, the moisture content was evaluated from the water evaporation rate of the non-inoculated medium. Dry weight of the substrate and moisture content were determined gravimetrically after drying of samples at $60^{\circ} \mathrm{C}$. To determine the water evaporation rates, non-inoculated medium was incubated at $30{ }^{\circ} \mathrm{C}$ for 7 days and was weighed every $24 \mathrm{~h}$. Based on the evaporation rate, $4 \%$ of moisture content was declined every $24 \mathrm{~h}$. The optimal biomass production requires atleast $50 \%$ moisture content (data not shown). Therefore, the moisture content was controlled throughout the incubation period ( 7 days) by starting experiment with $83 \%$ moisture content in the SSC. The production of biosurfactant was performed in triplicate $250 \mathrm{ml}$ Erlenmeyer flasks. To develop the SSC, $5 \mathrm{~g}$ of the dried substrate was transferred to $250 \mathrm{ml}$ Erlenmeyer flasks and mixed with $5 \mathrm{ml}$ of moistening media (salt solution) ( $\mathrm{pH} 7.0$ ). The composition of the salt solution was $\mathrm{NH}_{4} \mathrm{NO}_{3} 0.5 \%, \mathrm{NaCl} 0.9 \%, \mathrm{MgSO}_{4} \cdot 7 \mathrm{H}_{2} \mathrm{O} 0.1 \%$ and $\mathrm{pH}$ 7. The contents were sterilized by autoclaving at $103.4 \mathrm{kPa}$ for $20 \mathrm{~min}$. The sterilized solid substrate was inoculated with $2.5 \mathrm{ml}$ of the spore inoculums containing $1.7 \times 10^{5}$ spores. The contents were mixed properly and incubated at $30^{\circ} \mathrm{C}$ for 7 days. For the extraction biosurfactant, $40 \mathrm{ml}$ distilled water, $10 \mathrm{ml}$ chloroform:methanol (2:1) was added and stirred for $10 \mathrm{~min}$, filtered through cheese cloth and centrifuged (Eppendorf) at $9000 \mathrm{~g}$ for $10 \mathrm{~min}$. The cell free supernatant was collected and used for the screening of biosurfactant activity.

Optimization of biosurfactant production was carried out by search one at a time technique. Subsequently appropriate experimental models were developed in order to study the interactions between the factors. Factors such as carbon and nitrogen sources, $\mathrm{pH}$, temperature, amino acids, metal ions, inoculum size and salt concentration affecting the biosurfactant production were determined. The optimization process was completed with the effective concentration of chosen carbon and nitrogen source to maximize the production under SSC conditions. Most appropriate carbon and nitrogen sources were selected from the range of these sources used in the optimization. The SSC was conducted with $1 \%, 2 \%, 3 \%$ and $4 \%$ of the respective carbon and nitrogen sources. The glucosamine based biomass estimation (Sakurai et al., 1977) was used to extrapolate the biomass, since direct estimation of biomass is not possible in SSC.

In this study, the critical control factors influenced the biosurfactant production by Brevibacterium aureum MSA13 was used in the response surface methodology (RSM)-based experiments (Khuri and Cornell, 1987; Montgomery, 1991). In the experimental design, four variables (olive oil, acrylamide, ferric chloride and inoculum size) that have effect on the production of biosurfactant were identified by the optimization experiments. Each independent variable was investigated at a high $(+1)$ middle $(0)$ and a low $(-1)$ level. Runs of center points (control) were included in the matrix. 


\subsection{Chemical characterization of surface active compound}

For the purification of the active compound, acid precipitation followed by liquid-liquid extraction was performed using the SSC substrate with biomass. Extraction was started with the addition of $100 \mathrm{ml}$ distilled water to the SSC flasks and was agitated for $1 \mathrm{~h}$ at $200 \mathrm{rpm}$ at $30^{\circ} \mathrm{C}$ on an orbital shaker (Technico). The suspension was filtered through cheesecloth, the excess liquid being squeezed out manually. This procedure was done three times. The extract was centrifuged for $10 \mathrm{~min}$ at 12,500g (Eppendorf), the supernatant was collected and acidified with conc. $\mathrm{HCl}$ to attain $\mathrm{pH} 2.0$ and washed by deionized water two times to remove the remaining $\mathrm{HCl}$. Biosurfactant was extracted with an equal volume of solvents such as ethyl acetate, diethyl ether and dichloromethane. The resultant aliquot was concentrated to dryness in a rotary vacuum evaporator (Yamato DC 400) and the residue remained was tested for emulsification activity as described above. To purify the surface active compound, the concentrated extract was subjected to column chromatography on C18-reverse phase silica gel (230-400 mesh) with step wise elution with methanol from $65 \%$ to $100 \%$ at a flow rate of $0.5 \mathrm{ml} / \mathrm{min}$ at room temperature $\left(24^{\circ} \mathrm{C}\right)$. The active fraction was confirmed by the emulsification activity and the purity was checked by TLC. TLC was performed for proteins ( $n$-butanol:acetic acid:water 4:3:2), carbohydrates (chloroform:acetic acid:water 60:30:10) and lipids (chloroform:methanol:water 65:25:4). The resultant spots on the TLC plates were visualized by spraying of $50 \% \mathrm{H}_{2} \mathrm{SO}_{4}$ for carbohydrates and ninhydrin for amino acids. The TLC plates were exposed in an iodine chamber to visualize the lipid fractions. The column purified active fraction was used for GC-MS analysis. An Agilent GC-MS system equipped with a fused silica capillary tube was used to analyse the components in this active fraction. The data was processed by GC-MSD. Chemstation column condition was programmed as column oven temperature $150{ }^{\circ} \mathrm{C}(4 \mathrm{~min})-4^{\circ} \mathrm{C} / \mathrm{min}$, temperature of inject port $250^{\circ} \mathrm{C}$ and detector port $280^{\circ} \mathrm{C}$. The peaks of the gas chromatography were subjected to mass-spectral analysis. The spectra were analysed by NIST MS search (version 2.0) (included with NIST'02 mass-spectral library, Agilent p/n G1033A). Stability of the HPLC purified surface active compound at $0.4 \%$ $(w / v)$ in water was determined using the different concentration/ ranges of $\mathrm{NaCl}, \mathrm{pH}$ and temperatures.

\subsection{Microbially enhanced oil recovery (MEOR) - sand pack method}

The potential application of the biosurfactant in MEOR was evaluated using the modified 'sand pack column' technique described by Suthar et al. (2008). A vertical glass column of $20 \mathrm{~mm} \times 25 \mathrm{~mm} \times 85 \mathrm{~mm}$ dimensions with a sieve (100 $\mu \mathrm{m}$ pore size) and cap fixed at the bottom was packed with $150 \mathrm{~g}$ sand of $140 \mu \mathrm{m}$ particle size. The column was then saturated with heavy duty gear oil (density $0.918 \mathrm{~kg} / \mathrm{l})(50 \mathrm{ml})$. The potential of the isolated surfactant for oil recovery was estimated by pouring $50 \mathrm{ml}$ of aqueous solution of biosurfactant in the column. The amount of oil released was measured. The experiment was carried out at 30, 50 and $70^{\circ} \mathrm{C}$ to assess the influence of temperature on biosurfactant-induced oil recovery.

\subsection{Antimicrobial assay}

The extracted surface active compound, active fraction and the culture supernatant were tested for antimicrobial activity using well diffusion method (Gandhimathi et al., 2008). Extracted active compound was tested against human pathogens such as Candida albicans, Escherichia coli, Proteus mirabilis, hemolytic Streptococcus sp., Pseudomonas aeruginosa, Micrococcus luteus, Staphylococcus epidermidis, Enteribacter faecalis, Klebsiella pneumoniae, Bacillus sp. and
S. aureus obtained from clinical laboratories. Mueller Hinton agar (beef infusion solids $4.0 \mathrm{~g}$, starch $1.5 \mathrm{~g}$, casein hydrolysate $17.5 \mathrm{~g}$, agar $15.0 \mathrm{~g}$, final $\mathrm{pH} 7.4+/-0.2$ at $37^{\circ} \mathrm{C}$ ) was used for antimicrobial assay. The assay plates were prepared by spread plate technique with appropriate pathogen inoculums $\left(\approx 10^{4} \mathrm{CFU}\right)$. Using a sterile cork borer, a $7 \mathrm{~mm}$ well was made and $50 \mu \mathrm{l}(0.1 \mu \mathrm{g} / \mu \mathrm{l})$ of surface active compound was added in wells, incubated at $30^{\circ} \mathrm{C}$ for $24 \mathrm{~h}$. After incubation, the clear zone was measured and calculated.

\subsection{Biofilm formation assay}

Actinobacterial biofilm was developed as per the method of O'Toole and Kolter (1998) with some modifications. Briefly, $20 \mu \mathrm{l}$ of stationary phase culture e $(\sim 0.3$ at an OD at $600 \mathrm{~nm})$ was added to $2 \mathrm{ml}$ actinomycetes broth (Himedia) in 10 borosilicate glass tubes $(75 \mathrm{~mm}$ ). Then the tubes were incubated aerobically at room temperature without shaking for 5-6 days. After incubation nonadherent cells were removed by rinsing with distilled water. Then the biofilm were stained by the addition of required amount of $1 \%$ crystal violet for $25 \mathrm{~min}$ followed by rinsing with distilled water. Actinobacterial biofilm was also developed in the microtiter plates. The biofilm developed on the microtiter plates was stained with $1 \%$ crystal violet and observed under stereozoom microscope. Air-liquid interphase assay and motility assay were performed as per the previously described methods (Rashid and Kornberg, 2000).

\subsection{Analytical methods}

The emulsification index $\left(E_{24}\right)$ provides a rapid and reliable measure of the quantity of biosurfactant. The $E_{24}$ was determined as described by Nitchke and Pastore (2004). Kerosene was added to cell free broth in a ratio of $1: 1$ and vortexed vigorously for $2 \mathrm{~min}$. After $24 \mathrm{~h}$ of incubation, the height of the emulsified layer was measured and compared with the total height of the liquid layer and multiplied by $100\left(E_{24}\right)$. The protein content was estimated using the method of Lowry et al. (1951); carbohydrate and lipid by the methods of Chaplin and Kennedy (1994) and Sadasivam and Manickam (1991) respectively. To extrapolate the surfactant activity of purified compound with emulsification index, the surface tension was measured with a tensiometer using the duNouy procedure (Sigma) with a platinum ring at $24^{\circ} \mathrm{C}$. The surface tension-concentration plots were used to determine critical micelle concentrations (Randhir, 1997). In this study, SDS was used as standard.

\section{Results}

\subsection{Isolation and identification of biosurfactant producer MSA13}

This report is an outcome of biopropspecting of culturable actinobacteria from the marine sponge $D$. nigra. Among the 57 stable isolates, the strains MSA04, MSA10, MSA13, MSA19 and MSA21 were considered as potential biosurfactant producers. Among these, MSA04 and MSA13 were characterized a novel source of glycolipid and lipopeptide biosurfactants (Kiran, 2009). The scope of the present report focused on the production, chemical characterization and evaluation of MSA13 screened as potential biosurfactant producer based on the results of screening tests including hemolytic activity $(6 \mathrm{~mm})$, oil displacement $(8 \mathrm{~mm})$, lipase activity ( $78 \mathrm{U} / \mathrm{mg}$ ), positive drop collapsing test and emulsification activity (10\%). The isolate MSA13 was characterized as non-motile, Gram positive, spore-forming and MR positive. The isolate hydrolysed starch, chitin, gelatin, cellulose and tributyrin. The strain utilized glucose and not utilized mannitol. The isolate was sensitive to ciprofloxacin and chloramphenicol resistant to ampicillin. Taxonomic 


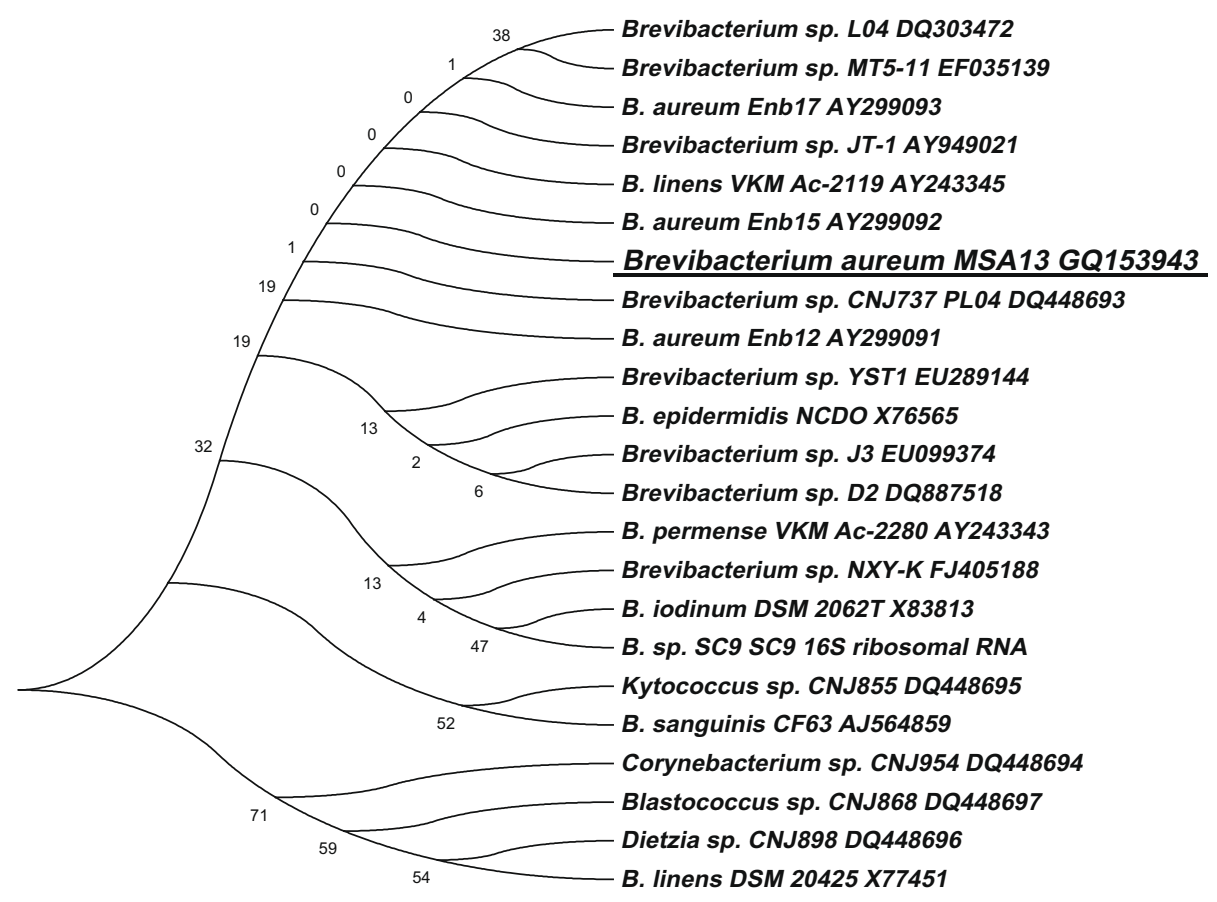

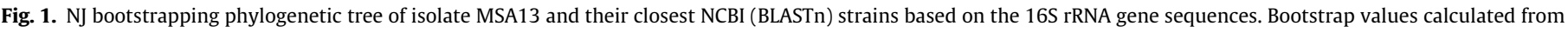
1000 resamplings using UPGMA are shown at the respective nodes when the calculated values were $50 \%$ or greater.

affiliation of the isolate was retrieved from classifier programme of Ribosomal Database Project II (RDPII) (http://rdp.cme.msu.edu/). Representative of maximum homologous (97-99\%) sequences of the isolate was obtained from seqmatch programme of RDPII and were used for the construction of phylogenetic affiliation. The isolate MSA13 showed unique branch between Brevibacterium sp. CNJ737 and B. aureum Enb15 (Fig. 1). The phylogenetic analysis and RDPII search showed the isolate as a Brevibacterium genus. Based on the morphological, biochemical characteristics, and phylogenetic analysis, the isolate MSA13 was identified as B. aureum MSA13.

\subsection{Biosurfactant production in SSC}

Among the substrates screened, pre-treated molasses was found to be the most suitable substrate for the production of biosurfactant by $B$. aureum MSA13. The production was increased to $25 \%$ in the SSC with pre-treated molasses as substrate followed by wheat bran (20\%), tannery pre-treated sludge (20\%), treated molasses (18\%), tannery treated sludge (15\%) and oil seed cake (15\%). Olive oil was found to be the best carbon source which significantly increased the biosurfactant production. The olive oil as carbon source and pre-treated molasses as substrate increased the biosurfactant production to $72 \%$ followed by wheat bran (70\%), treated molasses (68\%), oil seed cake (62\%), tannery pretreated sludge (54\%) and tannery treated sludge (48\%). The strain B. aureum MSA13 showed enhanced biosurfactant production (60\%) using acrylamide as nitrogen source. The enhanced production $>25 \%$ was observed on all the substrates used in the SSC development.

It was found that the $\mathrm{pH}$ had a definite influence on the production of biosurfactant by the strain B. aureum MSA13. Since the determination of $\mathrm{pH}$ in the SSC media is practically a difficult task, the media with various $\mathrm{pH}$ were developed using appropriate phosphate buffer instead of water. The enhanced biosurfactant production (55-70\%) by B. aureum MSA13 was attained at $\mathrm{pH}$ 7.0. The production was consistent at $\mathrm{pH} 7.0$ on all the substrates used. The production was drastically declined at lower $\mathrm{pH}$ when compare to the higher $\mathrm{pH} 9.0$, where the production was nearly stable. Since the marine microorganisms are obviously grown well at $\mathrm{pH} 7.0$, the increased $\mathrm{pH}$ might have not much affected the production, when compare to the lower $\mathrm{pH}$, where the production was drastically declined. The production of biosurfactant by $B$. aureum MSA13 was reached maximum at $30^{\circ} \mathrm{C}$ with pre-treated molasses as substrate. The strain showed maximum biosurfactant production with $2 \% \mathrm{NaCl}$ supplementation. Among the metal ions used for the development of SSC, the biosurfactant production by B. aureum MSA13 was increased significantly using $\mathrm{FeCl}_{3}$ with pre-treated molasses followed by oil seed cake as substrates. The amino acid glycine increased the emulsifying activity to 55\%. The moisture content required for B. aureum MSA13 for surfactant production was greater than $80 \%$. The strain showed maximum production in the substrate inoculated with $2.5 \mathrm{ml}$ inoculum. The inoculum was developed after 5 days of subculture in actinomycetes broth. The peak production was attained at $144 \mathrm{~h}$ of incubation under the optimized SSC conditions. The glucosamine based biomass estimation indicated that the biomass invariably reached the exponential phase on the 3rd day of growth and the stationary phase started on the 7th day of incubation.

In this study, the optimization process was completed with the effective concentration of chosen carbon and nitrogen source to maximize the production under SSC conditions. The biosurfactant production by $B$. aureum MSA13 was consistently increased on the substrates such as pre-treated molasses, treated molasses and wheat bran with $1 \%$ olive oil as carbon source. The pre-treated molasses shown to be the best choice of substrate for the maximum production of biosurfactant using $2 \%$ acrylamide as nitrogen source. Notably the production was consistent over the range of substrates such as treated molasses, tannery pre-treated sludge, tannery treated sludge, wheat bran and oil seed cake in slightly decreasing order. The maximum production of biosurfactant by B. aureum MSA13 occurred at a $\mathrm{C} / \mathrm{N}$ ratio of 0.5 envisaging that a higher amount of nitrogen source is required by the organism compared to that of the carbon source. 
Table 1

ANOVA analysis of the optimization of production by B. aureum MSA13.

\begin{tabular}{llc}
\hline Factors & Terms & $P$-value \\
\hline Olive oil & Linear & $0.0010^{* *}$ \\
Ferric chloride & Linear & $0.0019^{* *}$ \\
Inoculum size & Linear & $<0.0001^{* * *}$ \\
Olive oil and acrylamide & Interaction & $0.2876^{*}$ \\
Olive oil and ferric chloride & Interaction & $0.1295^{*}$ \\
Olive oil & Squared & $0.0019^{* *}$ \\
Acrylamide & Squared & $<0.0001^{* * *}$ \\
Ferric chloride & Squared & $0.0122^{* *}$ \\
Inoculum size & Squared & $0.0114^{* *}$ \\
\hline${ }^{*}$ Affecting terms. & & \\
${ }^{* * *}$ Significant. & & \\
More significant. & &
\end{tabular}

\subsection{Optimization of biosurfactant production using response surface methodology}

The $R^{2}$ value of 0.9543 which is closer to 1 shows the model to be stronger and it can better predict the response. The model was found to be significant with $p<0.0001$ and insignificant lack of fit (Table 1 ). The behavior of the system is explained by the following quadratic model equation:

$$
\begin{aligned}
Y= & 40.5-8.58 X_{1}+0.5 X_{2}-7.83 X_{3}+14.85 X_{4}+13 X_{1}^{2}-20.62 X_{2}^{2} \\
& +9.62 X_{3}^{2}+9.75 X_{4}^{2}-3.75 X_{1} X_{2}-5.5 X_{1} X_{3}+1.0 X_{1} X_{4} \\
& +1.25 X_{2} X_{3}+2.0 X_{2} X_{4}-3.25 X_{3} X_{4}
\end{aligned}
$$

The predicted value of $Y$ by the above explained quadratic model was found to be $79 \%$. The experimental value obtained was $86 \%$. The production of biosurfactant obtained as a result of a valid experimental design was found to be $7 \%$ higher than that of the predicted value. The critical control factors influence the production of biosurfactant includes olive oil, acrylamide, ferric chloride and inoculum size. A significant interactive influence of primary control factors such as olive oil and acrylamide was validated in the RSM design. The olive oil and acrylamide interactively and independently increase the production maxima over a stable area (Fig. 2). The metal ion, ferric chloride and inoculum size were interactively increasing the production and the stable production curve was attained with the influence of both factors (Fig. 3). Interestingly the production maxima was skewed towards the inoculum size evidenced that the production significantly influenced by inoculum size rather than metal ion. Based on the optimization experiments, it can be concluded that the biosurfactant production by $B$. aureum MSA13 was increased to threefold over the original isolate under SSC conditions with pre-treated molasses as substrate and olive oil, acrylamide, $\mathrm{FeCl}_{3}$ and inoculums size as critical control factors.

\subsection{Chemical characterization of biosurfactant}

The surfactive extract of $B$. aureum MSA13 contained $0.53 \mathrm{mg} /$ $\mathrm{ml}$ protein, $0.012 \mathrm{mg} / \mathrm{ml}$ carbohydrate and $4.886 \mathrm{mg} / \mathrm{ml}$ lipid. Based on the TLC analysis, protein and lipid fractions were separated (data not shown). The GC-MS analysis showed that the compound produced by $B$. aureum MSA13 was a lipopeptide derivative. The hydrophobic moiety envisaged to be an octadecanoic acid methyl ester (Fig. 4a). Retention times, relative intensities (\%) and EIMS of the relevant peaks are as follows: peak A: 14.247, 55, EIMS $m / z$ (\% rel. intensity), 300 (15), 255 (15), 200 (16), 150 (20), 85 (70), 75 (100) 55 (30) and 40 (35). The peptide part was predicted as a probable short sequence of four amino acids including pro-leu-gly-gly (Table 2). Thus, the lipopeptide surfactant produced by $B$. aureum MSA13, composed probably of four amino

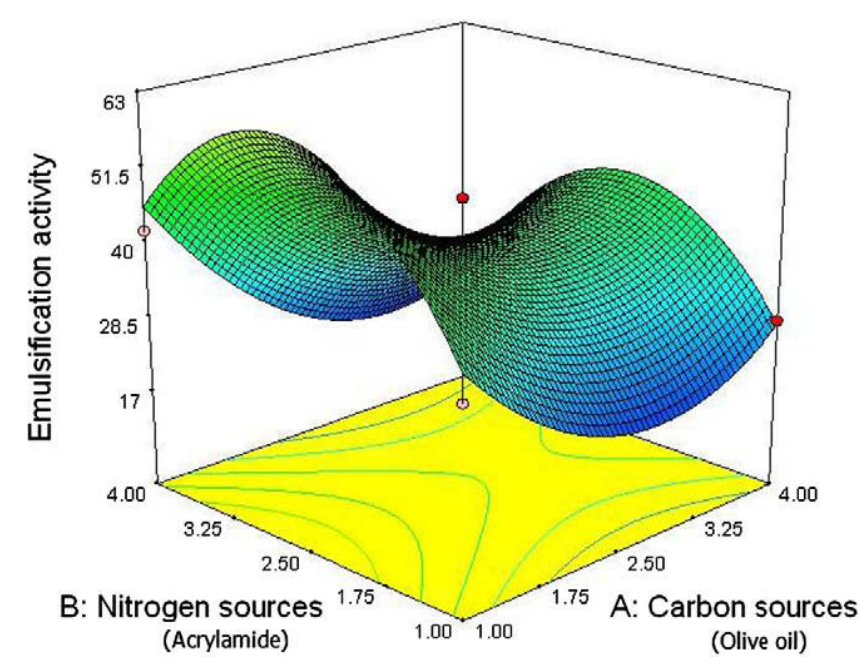

Fig. 2. Contour plot of the interaction between the olive oil (carbon source) and acrylamide (nitrogen source) on the production of biosurfactant in SSC by B. aureum MSA13.

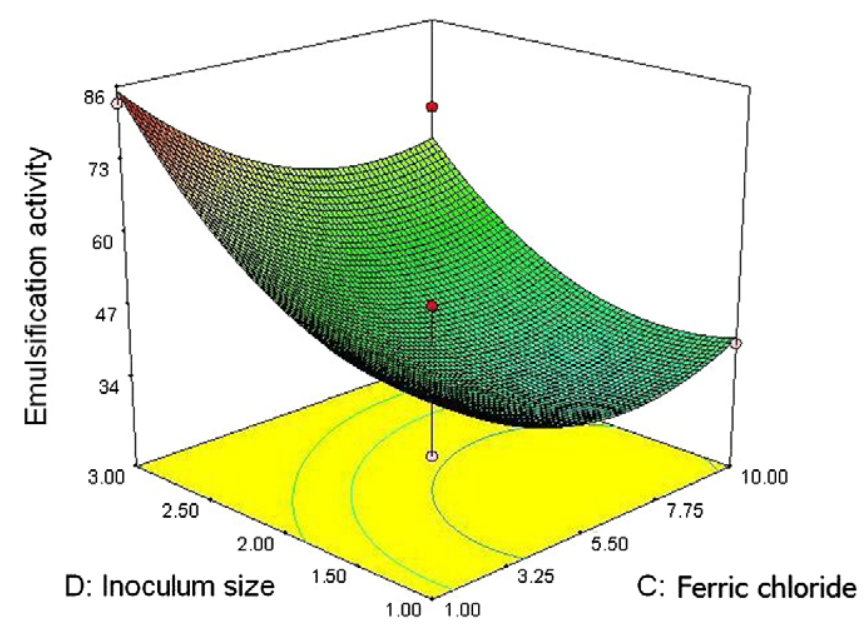

Fig. 3. Contour plot of the interaction between the ferric chloride and inoculum size on the production of biosurfactant in SSC by B. aureum MSA13.

acids coupled to one molecule of octadecanoic acid methyl ester (Fig. 4b). The crystalline structure of biosurfactant was observed under light microscopy and found that the crystals have featherlike appearance (Fig. 4c). The newly characterized lipopeptide biosurfactant produced by $B$. aureum MSA13 was named as "brevifactin", since the compound was first demonstrated from Brevibacterium strain $B$. aureum MSA13. The biosurfactant produced by the marine $B$. aureum MSA13 was stable over a range of temperatures particularly stable even after autoclaving $\left(121^{\circ} \mathrm{C}\right)$. The biosurfactants were invariably stable over $\mathrm{pH} 5-9$. The stability was high at alkaline $\mathrm{pH}$ compare to lower $\mathrm{pH}$ values. Considering the marine strains, $\mathrm{NaCl}$ concentration was inevitable factor for the production of biosurfactant. The purified biosurfactant from the strain B. aureum MSA13 was stable over $\mathrm{NaCl}$ concentrations (1-5\%). The emulsification index of biosurfactant produced by $B$. aureum MSA13 was invariably high over the synthetic surfactants such as SDS, Tween 20 and Tween 80 . The average surface tension of pure water at $24{ }^{\circ} \mathrm{C}$ was $72.54 \pm 0.74 \mathrm{mN} / \mathrm{m}$, SDS $(0.3 \mathrm{mg} / \mathrm{ml})$ showed the lowering surface tension activity to $30.12 \pm 0.26 \mathrm{mN} / \mathrm{m}$ and the purified compound $(0.1 \mathrm{mg} / \mathrm{ml})$ showed the lowering surface tension activity to $28.56 \pm 0.72 \mathrm{mN} / \mathrm{m}$. The purified surfactant concentration in the extract was $18 \mathrm{~g} / \mathrm{l}$. 


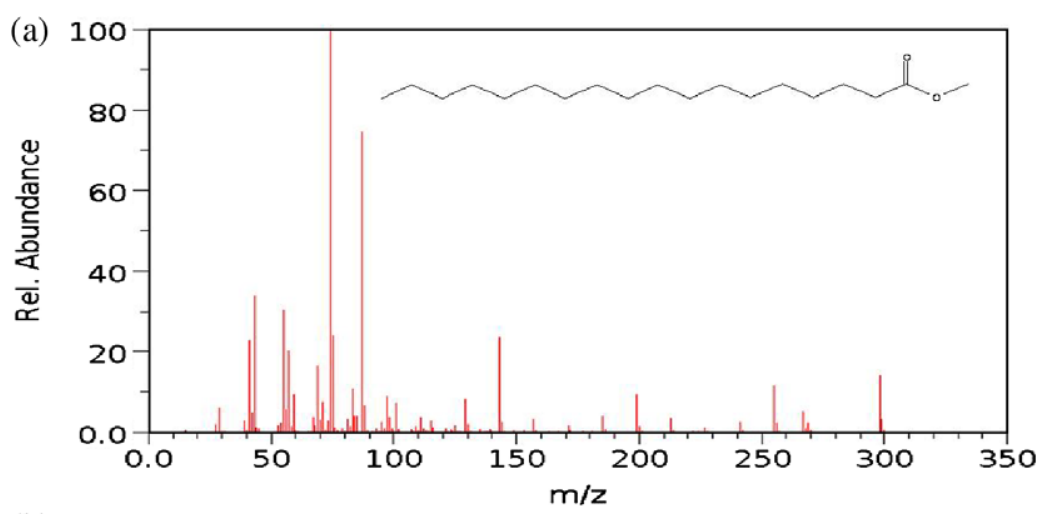

(b)

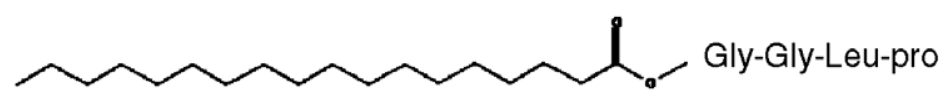

(c)

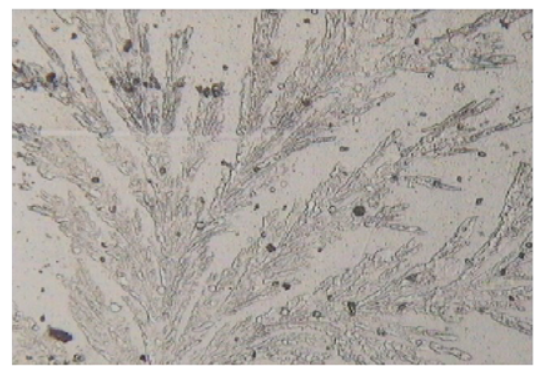

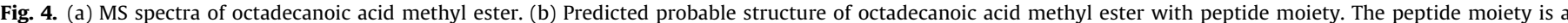

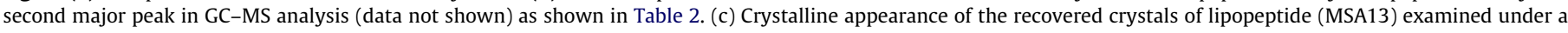
light microscope at $40 \times$.

Table 2

Predicted compounds and major fractions of GC-MS data of B. aureum MSA13.

\begin{tabular}{llll}
\hline No. & Compound name & Formula & $\begin{array}{l}\text { Molecular } \\
\text { weight }\end{array}$ \\
\hline 1 & Heptacosanoic acid, 25-methyl-, methyl ester & $\mathrm{C}_{29} \mathrm{H}_{58} \mathrm{O}_{2}$ & 438 \\
2 & Heptacosanoic acid, 26-methyl-, methyl ester & $\mathrm{C}_{29} \mathrm{H}_{58} \mathrm{O}_{2}$ & 438 \\
3 & Octanoic acid, methyl ester (CAS) & $\mathrm{C}_{9} \mathrm{H}_{18} \mathrm{O}_{2}$ & 158 \\
4 & Hexadecanoic acid, methyl ester (CAS) & $\mathrm{C}_{17} \mathrm{H}_{34} \mathrm{O}_{2}$ & 270 \\
5 & Decanoic acid, methyl ester (CAS) & $\mathrm{C}_{11} \mathrm{H}_{22} \mathrm{O}_{2}$ & 186 \\
6 & Nonanoic acid, 9-oxo-, methyl ester (CAS) & $\mathrm{C}_{10} \mathrm{H}_{18} \mathrm{O}_{3}$ & 186 \\
7 & Pro-leu-gly-gly-Amine & $\mathrm{C}_{15} \mathrm{H}_{27} \mathrm{O}_{4} \mathrm{~N}_{5}$ & 341 \\
\hline
\end{tabular}

\subsection{Phylogenetic analysis of pks gene type II fragment}

Among the biosynthetic genes ( $p k s, n r p s, r h l b, s f p$ ) screened, the type II $p k s$ was amplified in the PCR reaction using the DNA of $B$. aureum MSA13 as template. The tBLASTx program showed the partial pks gene cds of $B$. aureum MSA13 (GenBank accession number GQ153948) was similar to putative ketasynthase domain of Streptomyces taxa. The findings of this study clearly evidenced that the biosynthetic pathway of biosurfactant synthesis in marine actinobacterium is very unique, which do not have any precedence with surfactive genes present in Pseudomonas sp. and Bacillus sp.

\subsection{Microbially enhanced oil recovery}

The MEOR process was carried out by the sand pack method. Hydrocarbon saturated sand pack column was treated with the biosurfactant extract and subsequently incubated at 30, 50 and $70{ }^{\circ} \mathrm{C}$. This caused release of the hydrocarbon from the column. The biosurfactants produced by the strain B. aureum MSA13 was highly effective on the recovery of crude oil. The oil recovery processes stable between the temperatures of 30 and $70^{\circ} \mathrm{C}$.

\subsection{Antimicrobial activity}

Antimicrobial activity of the ethyl acetate extract, column purified fraction and cell free supernatant of B. aureum MSA13 showed a broad spectrum of activity against the pathogenic microbes tested. The results are shown in Fig. 5. The column purified fraction showed highest activity against $C$. albicans followed by $K$. pneumoniae.

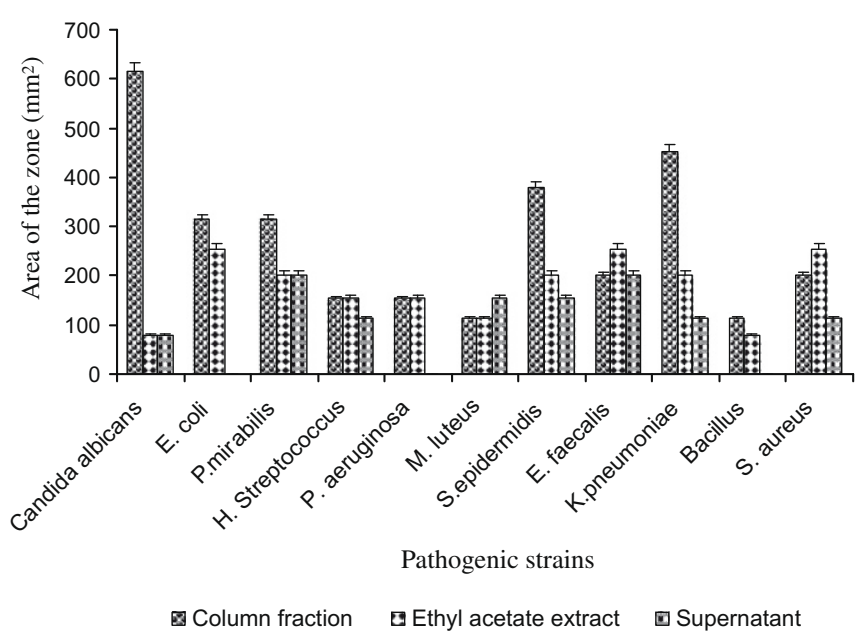

Fig. 5. Antimicrobial activity of $B$. aureum MSA13 against clinical pathogens. 


\subsection{Biofilm forming capacity of B. aureum MSA13 on various surfaces}

The biofilm forming capacity of the isolate B. aureum MSA13 was analysed in the solid surface of glass tubes. The isolate $B$. aureum MSA13 showed the maximum binding capacity on both surface of glass tubes and polystyrene plates. The biofilm producer primarily initiates biofilm at the gap between air and liquid interfaces. i.e., biofilm formation initiated in between the gap of solid and liquid surface and finally matures into biofilm. Mainly the aerobic colonies form aggregation onto the interphase air and liquid medium meeting junction. This system provides nutrients as well as maintains aerobic state which leads to microcolony formation that matured into biofilm structure with the production of high amounts of extra-cellular polysaccharides. The isolate $B$. aureum MSA13 showed the three motility indexes tested including swimming, swarming and twitching motilities.

\section{Discussion}

Satpute et al. (2008) suggested that single screening method is not suitable to identify all types of biosurfactants and recommended more than one screening methods should be included in the primary screening as to identify potential biosurfactant producers. Therefore, in this study, drop collapsing test, oil displacement test, lipase activity and emulsification activity were used to screen the biosurfactant producer. Among the four methods, lipase was not included in the previous reports on the screening of biosurfactant producers. According to Kokare et al. (2007), lipase acts on water-oil surfaces and therefore it was suggested that actinomycetes showed the presence of lipases are able to produce bioemulsifier. In this study, the strain Brevibacterium MSA13 showed positive results in all the four screening methods used.

Biosurfactants are products of microbial metabolism and therefore it is possible to produce a commercially viable biosurfactant using low-cost raw materials or high-pollutant wastes. Because of the escalating costs of waste treatment and disposal, as well as increasing societal interest in reducing consumption and waste production, a decrease in both is highly desirable and beneficial. The potential of industrial wastes in the development of SSC for the production of biosurfactant from marine actinobacterium was demonstrated for the first time. Industrial effluents have recently shown good promise as potential substrates for biosurfactant production. Selecting an alternative resource involves finding a residue with the right balance of nutrients to support optimal growth and production. In India, distillery industries have become a major source of pollution, as $88 \%$ of its raw materials are converted into waste and discharged into the water bodies, causing water pollution. The waste water from distilleries carry appreciable organic load. The spent wash is colored, highly acidic with very offensive odor, which poses serious environmental problems. Similarly, alcohol production has reached the 2.7 billion litre mark, which generates 40 billion litres of distillery spent wash. This massive quantity of effluent, if disposed untreated can cause considerable stress on the water course leading to widespread damage to aquatic life (Joshi, 1997). Considering the two prime industrial outputs including distilleries and tanneries in the nearby locality of Bharathidasan University, in this study aimed to develop novel processes to transform these industrial wastes into useful products. Biosurfactant production using molasses, or whey as a carbon source under shaking mode has already been reported (Dubey and Juwarkar, 2001). The production of biosurfactant under solid state cultivation with $B$. aureum MSA13 was increased to threefold over the original isolate under SSC conditions with pre-treated molasses as substrate and glucose, acrylamide, $\mathrm{FeCl}_{3}$ and inoculums size as critical control factors. Babu et al. (1996) studied the specific growth rates of $P$. aeruginosa strain BS2 and specific formation rates of rhamnolipid biosurfactants from distillery and whey wastes and synthetic medium. However, the production process using industrial waste residues in SSC has not been reported.

Acrylamide $3 \%(\mathrm{w} / \mathrm{w})$ as nitrogen source increased the production of biosurfactant significantly followed by beef extract as alternate nitrogen source. This report would be the first on the use of acrylamide as nitrogen source. Acrylamide, a neurotoxic monomer with extensive industrial applications was found to be degraded by the microorganisms present in a tropical garden soil. A bacterium capable of degrading acrylamide was isolated from this soil by enrichment (Shanker et al., 1990). Acrylamide was used a nitrogen source to stimulate methanogenesis (Haveroen et al., 2005) and as organic nitrogen source for soil microorganisms (Kay-Shoemaker et al., 1998). However, its application as nitrogen source in SSC and/or bioprocess optimization has not been reported. The present report brings out a new horizon on the microbial degradation/ waste utilization process for the removal of acrylamide from the environment.

The strain B. aureum MSA13 utilized up to $20 \%$ of $\mathrm{FeSO}_{4}$ and further increase in the metal concentration decrease the activity. Such high concentration of metal has never been reported for the production of biosurfactant. Wei and Chu (1998) recommended raising iron concentrations from the micromolar to the millimolar level to greatly enhance the surfactin production from $B$. subtilis ATCC 21332. Increasing the magnesium concentration to $20 \%$ inhibits the biosurfactant activity but trace amount of magnesium is required for biosurfactant production. The moisture content required for this strain under SSC was found to be greater than $80 \%$. The strain utilizes the amino acid, glycine for enhanced biosurfactant production. In this study, the SSC was developed successfully to increase the biosurfactant production substantially. Based on the present results, the SSC would be a preferred bioprocess for the optimization and production of biosurfactant by marine actinobacteria.

The strain B. aureum MSA13 produced exceptionally a lipopeptide biosurfactant with a hydrophobic moiety of octadecanoic acid methyl ester and a peptide part contained a short sequence of four amino acids including pro-leu-gly-gly. The complete chemical characterization of the compound is under progress. The newly characterized lipopeptide biosurfactant produced by $B$. aureum MSA13 was named as "brevifactin", since the compound was first demonstrated from Brevibacterium stain MSA13. The predicted structure of lipopeptide was different from other lipopeptides reported so far. A large number of cyclic lipopeptide including decapeptide antibiotics (gramicidine) and lipopeptide antibiotics (polymyxins) produced by Bacillus brevis (Marahiel et al., 1977) possess remarkable surface active properties. The cyclic lipopeptide surfactin produced by $B$. subtilis is one of the most powerful biosurfactant known today. It is composed of a seven amino acids ring structure coupled to one molecule of 3-hydroxy-13, methyltetradecanoic acid. The lipopeptide biosurfactant are most prominently known as surfactin produced mostly by the Bacillus sp. Despite similar global structures, surfactins, iturins and fengycins differ in some aspects regarding their biological activities. For instance, iturins and fengycins display a strong antifungal activity, while surfactins are not fungitoxic by themselves. Surfactins show weak antibacterial properties but iturins may be strongly inhibitory to the growth of some gram-positive bacteria. The lipopeptide biosurfactant produced by B. aureum MSA13 was a broadspectrum antimicrobial compound. Surfactins, but not iturins, are involved in biofilm formation by $B$. subtilis cells, suggesting specific surface- and membrane-active properties for these lipopeptides (Hofemeister et al., 2004). The biofilm producer primarily initiates biofilm at the gap between air and liquid interfaces. Considering the action of biosurfactants in air-liquid interfaces, the lipopeptide 
biosurfactant produced by the strain $B$. aureum MSA13 might have a functional role on its biofilm formation and stability. Biosurfactant production by Brevibacterium sp. isolated from oil contaminated soil and its effect on various carbon sources are reported previously (Samadi et al., 2007). This study is first report on the optimization and purification of lipopeptide biosurfactant produced by a marine $B$. aureum in SSC.

Biosurfactants are promising environmental molecules for bioremediation purposes; therefore, the stability of biosurfactants at high temperature, salinities, and over a wide range of $\mathrm{pH}$ was studied. One of the significant findings of this study was the thermostability of biosurfactant produced by B. aureum MSA13. The biosurfactant produced by $B$. aureum MSA13 was stable even at autoclaving. Such extreme stability was reported by AbdelMawgoud et al. (2008) for the P. aeruginosa strain. The thermal stability of the biosurfactants increased the scope of its application in a broader perspective including at conditions where high temperatures prevail as in the MEOR processes. Considering the need of halotolerant strains and biosurfactants for the bioremediation of oil contaminated sites (oil spills), it is mandatory to screen and develop potential biosurfactant producers from the marine environment. It was found that the biosurfactant produced by the marine actinobacterium was stable at high $\mathrm{NaCl}$ (up to $5 \%$ $\mathrm{NaCl}$ ). Chemical surfactants, however, are deactivated by $2-3 \%$ salt concentration (Bognolo, 1999).

\section{Conclusion}

Based on the present findings, the SSC using industrial wastes as substrates would be an ideal process for the production of lipopeptide biosurfactant. Considering the growing concern over the solid waste management challenges, the SSC can be used as a cleaner bioprocess for the utilization of industrial waste as alternate substrate. The presence of pks II gene in B. aureum MSA13 envisages the possible biosynthesis of secondary metabolites including antibiotics with surfactive properties. The biosurfactant produced by the $B$. aureum MSA13 was characterized as lipopeptide derivative, which ultimately formed a potential source over the chemical surfactants. Based on the findings, the brevifactin can be used in the MEOR processes particularly in the marine environments.

\section{Acknowledgements}

GSK is thankful to CSIR, New Delhi for the award of Senior Research Fellowship. This paper is an outcome of CSIR Project No. 38(1128)/06/EMR-II.

\section{Appendix A. Supplementary data}

Supplementary data associated with this article can be found, in the online version, at doi:10.1016/j.biortech.2009.11.023.

\section{References}

Abdel-Mawgoud, A.M., Aboulwafa, M.M., Hassouna, N.A., 2008. Characterization of surfactin produced by Bacillus subtilis isolate BS5. Appl. Biochem. Biotechnol. 150, 289-303.

Babu, P.S., Vaidya, A.N., Bal, A.S., Kapur, R., Juwarkar, A., Khanna, P., 1996. Kinetics of biosurfactant production by Pseudomonas aeruginosa strain BS2 from industrial wastes. Biotechnol. Lett. 18, 263-268.

Bognolo, G., 1999. Biosurfactants as emulsifying agents for hydrocarbons. Colloid Surf. Physicochem. Eng. Aspect. 152, 41-52.

Chaplin, M.F., Kennedy, J.F., 1994. Carbohydrate Analysis a Practical Approach, second ed. IRL Press, Oxford. pp. 1-36.

Dubey, K., Juwarkar, A., 2001. Distillery and curd whey wastes as viable alternative sources for biosurfactant production. World J. Microbiol. Biotechnol. 17, 61-69.

Ferrara, G.B., Murgia, B., Parodi, A.M., Valisano, L., Cerrano, C., Palmisano, G., Bavestrello, G., Sara, M., 2006. The assessment of DNA from marine organisms via a modified salting-out protocol. Cell. Mol. Biol. Lett. 11, 155-160.
Gandhimathi, R., Arunkumar, M., Selvin, J., Thangavelu, T., Sivaramakrishnan, S. Seghal Kiran, G., Shanmughapriya, S., Natarajaseenivasan, K., 2008. Antimicrobial potential of sponge associated marine actinomycetes. J. Mycol. Med. 18, 16-22.

Haveroen, M.E., MacKinnon, M.D., Fedorak, P.M., 2005. Polyacrylamide added as a nitrogen source stimulates methanogenesis in consortia from various wastewaters. Water Res. 39, 3333-3341.

Hofemeister, J., Conrad, B., Adler, B., Hofemeister, B., Feesche, J., Kucheryava, N. Steinborn, G., Franke, P., Grammel, N., Zwintscher, A., Leenders, F., Hitzeroth, G., Vater, J., 2004. Genetic analysis of the biosynthesis of non-ribosomal peptideand polyketide-like antibiotics, iron uptake and biofilm formation by Bacillus subtilis A1/3. Mol. Genet. Genomics 272, 363-378.

Joshi, H.C., 1997. Utilizing distillery effluents for agricultural production. Invent Intell. 32, 281-287.

Kay-Shoemaker, J.L., Watwood, M.E., Lentz, R.D., Sojka, R.E., 1998. Polyacrylamide as an organic nitrogen source for soil microorganisms with potential effects on inorganic soil nitrogen in agricultural soil. Soil Biol. Biochem. 30, 1045-1052.

Khuri, A.I., Cornell, J.A., 1987. Response Surfaces: Design and Analyses. Dekker, New York.

Kiran, G.S., 2009. Development of Novel Biosurfactants from Marine Actinobacteria: Process Optimization, In Vitro Evaluation and Molecular Analysis. Ph.D. thesis Bharathidasan University, Trichy, India.

Kiran, G.S., Hema, T.A., Gandhimathi, R., Selvin, J., Manilal, A., Sujith, S. Natarajaseenivasan, K., 2009. Optimization and production of a biosurfactant from the sponge-associated marine fungus Aspergillus ustus MSF3. Colloids Surf. B: Biointerfaces 73, 250-256.

Kokare, C.R., Kadam, S.S., Mahadik, K.R., Chopade, B.A., 2007. Studies on bioemulsifier production from marine Streptomyces sp. S1. Ind. J. Biotechnol. 6, 78-84.

Lechavalier, M.P., Lechavalier, H.A., 1970. Chemical composition as a criterion in the classification of aerobic actinomycetes. Int. J. Syst. Bacteriol. 20, 435-443.

Lowry, O.H., Rosebrought, N.J., Farr, A., Randall, R.J., 1951. Protein measurement with the folin phenol reagent. J. Biol. Chem. 139, 265-274.

Makkar, R.S., Cameotra, S.S., 1999. Biosurfactant production by microorganisms on unconventional carbon sources - a review. J. Surfactants Deterg. 2, 237-241.

Marahiel, M., Denders, W., Krause, M., Kleinkauf, H., 1977. Biological role of gramicidin $\mathrm{S}$ in spore functions. Studies on gramicidin-S negative mutants of Bacillus brevis 9999. Eur. J. Biochem. 99, 49-52.

Montgomery, D.C., 1991. Analysis and Design of Experiments, fourth ed. Wiley, New York.

Morikawa, M., Daido, H., Takao, T., Marato, S., Shimonishi, Y., Imanaka, T., 1993. A new lipopeptide biosurfactant produced by Arthrobacter sp. strain MIS 38. J. Bacteriol. 175, 6459-6466.

Nitchke, M., Pastore, G.M., 2004. Biosurfactant production by Bacillus subtilis using cassava processing effluent. Appl. Biochem. Biotechnol. 112, 163-172.

Olivera, N.L., Commendatore, M.G., Delgado, O., Esteves, J.L., 2003. Microbia characterization and hydrocarbon biodegradation potential of natural bilge waste microflora. J. Ind. Microbiol. Biotechnol. 30, 542-548.

O’Toole, G.A., Kolter, R., 1998. Flagellar and twitching motility are necessary for Pseudomonas aeruginosa biofilm development. Mol. Microbiol. 30, 295-304.

Paraszkiewicz, K., Kanwal, A., Dlugonski, J., 1992. Emulsifier production by steroid transforming filamentous fungus Curvularia lunata, growth and product characterization. J. Biotechnol. 92, 287-294.

Randhir, S.M., 1997. Utilization of molasses for biosurfactant production by two Bacillus strains at thermophilic conditions. JAOCS 74, 887-889.

Rashid, M.H., Kornberg, A., 2000. Inorganic polyphosphate is needed for swimming, swarming, and twitching motilities of Pseudomonas aeruginosa. Proc. Natl. Acad. Sci. USA 97, 4885-4890.

Sadasivam, S., Manickam, A., 1991. Biochemical Methods, second ed. New Age International Limited Publishers, New Delhi.

Sakurai, Y., Lee, T.H., Shiota, H., 1977. On the convenient method for glucosamine estimation in Koji. Agric. Biol. Chem. 41, 619-624.

Samadi, N., Abadian, N., Akhavan, A., Fazeli, M.R., Tahzibi, A., Jamalifar, H., 2007. Biosurfactant production by the strain isolated from contaminated soil. J. Biol. Sci. 7, 1266-1269.

Satpute, S.K., Bhawsar, B.D., Dhakephalkar, P.K., Chopade, B.A., 2008. Assessment of different screening methods for selecting biosurfactant producing marine bacteria. Ind. J. Mar. Sci. 37, 243-250.

Selvin, J., 2009. Exploring the antagonistic producer Streptomyces MSI051: implications of polyketide synthase gene type II and a ubiquitous defense enzyme phospholipase A2 in host sponge Dendrilla nigra. Curr. Microbiol. 58, 459-463.

Selvin, J., Shanmughapriya, S., Gandhimathi, R., Seghal Kiran, G., Rajeetha Ravji, T. Natarajaseenivasan, K., Hema, T.A., 2009. Optimization and production of novel antimicrobial agents from sponge associated marine actinomycetes Nocardiopsis dassonvillei MAD08. Appl. Microbiol. Biotechnol. 83, 435-445.

Shanker, R., Ramakrishna, C., Seth, P.K., 1990. Microbial degradation of acrylamide monomer. Arch. Microbiol. 154, 192-198.

Suthar, H., Hingurao, K., Desai, A., Nerurkar, A., 2008. Evaluation of bioemulsifier mediated microbial enhanced oil recovery using sand pack column. J. Microbiol. Methods 75, 225-230.

Wei, Y.H., Chu, I.M., 1998. Enhancement of surfactin production in iron-enriched media by Bacillus subtilis ATCC 21332. Enzyme Microb. Tech. 22, 724-728.

Youssef, N.H., Dunacn, K.E., Nagle, D.P., Savage, K.N., Knapp, R.M., McInerney, M.J., 2004. Comparison of methods to detect biosurfactant production by diverse microorganism. J. Microbiol. Methods 56, 339-347. 